\title{
0 realismo como estratégia e fator de identidade no cinema contemporâneo
}

Realism: strategy and factor of identity in contemporary cinema

\author{
LUIZA CRISTINA LUSVARGHI \\ Professora da Universidade Federal de Pernambuco e bolsita PRODOC do PPGCOM/UFPE \\ E-mail: lumecom@uol.com.br
}

\section{Resumo}

Na maior parte de sua história, a principal tendência estética definidora do cinema europeu foi o realismo, um dos meios utilizados para se diferenciar de fábrica de sonhos hollywoodiana. No Brasil, apesar do fluxo descontinuado da produção, não foi diferente. No entanto, o realismo não é necessariamente o melhor veículo para discutir identidade cultural e ideologia. As produções realistas contemporâneas são híbridas, e usam a verossimilhança como artifício.

Palavras-Chave: realismo; identidade cultural; cinema contemporâneo, nacionalismo.

Realismo e contemporaneidade

Distantes do realismo brechtiniano, do realismo socialista do período stalinista, ou ainda das discussões ideológicas do Cinema Novo, filmes nacionais recentes como Bicho-de-Sete Cabeças (2001), Meu nome não é Johnny (2008), Carandiru (2003), O Invasor( 2002), "Cidade de Deus" (2002) e o polêmico Tropa de Elite (2007) -, tiveram seus argumentos baseados em livrosreportagem ou romances que exploram a realidade do país e são, pretensamente, baseados em fatos reais e se valem disso para atrair o público.

Neste sentido, Tropa de Elite, de José Padilha, é um fenômeno midiático. Ganhou o público em cópia pirata vendida pelos camelôs, se alimentou do sucesso de seu protagonista, o ator Wagner Moura, à época galã de uma das novelas da Rede Globo, causou acalorados debates envolvendo intelectuais e o público e, pela primeira vez na história do País, transformou um policial linha-dura, um autêntico Bruce Willis caboclo, em herói nacional, popularizando um dos destacamentos policias mais violentos, o BOPE, entre os jovens - o carnaval carioca e até o pernambucano exibem fantasias baseadas no estilo Tropa de Elite, camisetas e até biquínis. Cidade de Deus, baseado no romance homônimo, embora ficcional, também se vale totalmente desta referência, tanto no livro, escrito por Paulo Lins, ex-morador do conjunto habitacional onde se passa o romance, e baseado em pesquisa realizada pelo autor juntamente com a socióloga Alba Zaluar, quanto no filme, em que entrevistas feitas com os verdadeiros personagens são reproduzidas em áudio junto com os créditos finais.

Um outro desdobramento dessa tendência, representada por obras como Quanto Vale ou é por quilo, (2005), de Sérgio Bianchi, 
também já chamada de filmeensaio, na medida em que o ponto de partida não é a notícia do dia, mas o intuito é discutir a realidade nacional, também parece se alimentar da realidade. A proposta narrativa, entretanto, não é a da verossimilhança, como ocorre em Tropa de Elite, de José Padilha, mas sim a do discurso que se articula a partir das imagens, que no caso do filme de Bianchi, mesclam períodos históricos diferentes e a um determinado ponto, rompem com qualquer estrutura de tempo linear - como na seqüência em que as duas Armindas do filme, a do conto de Machado de Assis, e a do roteiro de Dudu Benaim, interpretadas pela atrizAna Carbatti, se traduzem em uma única personagem que num dado momento vaga com a emblemática máscara de Flandres pelas ruas, num presente atemporal.

No início do cinema nacional, a crônica policial e a sátira política sempre foram fontes de inspiração. A crônica policial alentou as primeiras produções brasileiras de sucesso, e os títulos dos filmes praticamente resumem a crônica policial daquele tempo - a professorinha de São Paulo que anavalhou o noivo na terça-feira de carnaval é o argumento de Tragédia Paulista", a estória do estrangulador Miguel Trad que esquartejou sua vítima e a despachou dentro da mala, $O$ Crime da Mala (Salles Gomes, 1980, p. 32). As trilhas sonoras das produções estrangeiras eram gravadas, mas os filmes brasileiros eram cantados ao vivo. $\mathrm{O}$ ponto alto do gênero cantado e falado foram os filmes-revista que faziam paródia do governo.

O realismo foi, desde a década de 20, mais do que um conceito, uma das estratégias do cinema europeu para se diferenciar das produções hollywoodianas. Durante a globalização dos 90, essa competição atingiu níveis de acirramento nunca experimentados anteriormente, com o fim da Guerra Fria, o acesso ao mercado de países outrora pertencentes ao bloco socialista, o fortalecimento da União Européia. Os maiores paísesprodutores europeus são França, Itália, Alemanha, Espanha e GrãBretanha. E apesar da dificuldade de competirem com a produção norte-americana em seu próprio mercado, não há dúvida de que a competição acabou levando mercados regionais a soluções criativas, como ocorreu com o movimento Dogma 95, na Escandinávia, em meio a outras tendências (CHAUDURI, 2005, p.14). E mesmo o movimento neorealista de 1940, que teve um impacto enorme sobre a Nouvelle Vague e a British New Waves nas décadas de 50 e 60 , continuam a influenciar as concepções de realismo ainda hoje, bem como o cinema-vérité. Apesar disso outras influências estilísticas se manifestam, como a propalada "estética MTV", utilizada para nomear obras de edições semelhantes a dos videoclipes, condensando por vezes materiais de origem diversa numa mesma narrativa, na forma de pastiche, interferindo na forma de narrar esta realidade, como o cinema du look, de Luc Besson e Léos Carax, ou o filme de Meirelles e de Padilha. Mesmo porque, com freqüência, o realismo não é o melhor veículo para discutir identidades culturais ou mesmo identidades nacionais européias. A esta proposta muitos vão chamar de anti-realismo. O surrealismo, que emergiu como movimento de vanguarda na França da década de 20, é também uma influência forte 
em diversas cinematografias européias, particularmente na Espanha e República Checa.

Surrealism aims to represent the forces of the uncounscious, including dreams. The fantastical coutertendency in European cinema further emerges through magic realism, which has Latin American novelistic roots and combines historical realism with mith and fantasy. Although the heritage film, Second World War film and comedy may be considered pan-European genres, contemporary European films borrow extensively from international neo-noir, Hollywood thrillers and Vietnam war films. These, togheter with stylistic influences like MTV, mofify the realist impulse. (CHAUDHURI, 2005, p. 17)

O Surrealismo estaria presente tanto em obras como "Delicatessen" (1991), de Marc Caro e Jean-Pierre Jeunet, na França, quanto em obras de paises que pertenceram ao bloco comunista, como a República Checa, em obras como as de Jan Svankmajer - Alice (1988), Faust (1994), Conspirators of Pleasure (1996), Little Otik (2000) and Lunacy (2005), este último baseado em Edgar Allan Poe - mesmo porque sintomaticamente, esta tendência se revelou nestas regiões como uma saída ao controle dos partidos comunistas. Outro exemplo, este mais inclinado a um realismo mágico, é o da obra de Emir Kusturica,

As influências do vídeo e do documentário.

Os filmes realistas frequentemente utilizam recursos narrativos do documentário para contar suas histórias, e do teledocumentário. É a edição em imagens, possibilitada pelo surgimento do videoteipe, que insere a televisão na linguagem do documentarismo, "gênero de produção audiovisual que passou a ter esse nome em 1920. Neste ano, Roberto Flaherty contou a história da vida real de uma família de esquimós, no filme 'Nanuk' o esquimó (Port Huton)". (LAGE, 1997, p. 29).

$O$ grande precursor do documentário foi o soviético Dziga Vertov, jovem cinegrafista que em 1920 cria o conceito de cinemaverdade, ou cinema-verité. A experiência fundada por esses pioneiros, que incluem ainda o documentarista inglês John Grierson, com Barcos de Pesca, em 1929, e o alemão Walter Ruttmann, autor de Berlim, sinfonia de uma metrópole e de Melodia do mundo, lançados respectivamente em 1927 e 1929, e também os franceses Marc Allegret (Viagem ao Congo, 1926) e Leon Poirrier ( $O$ cruzeiro negro, mesmo ano), vai permitir ao gênero telejornalístico dispor de uma possibilidade muito maior que a do jornalismo gráfico moderno, em larga escala inspirado pelo construtivismo.

É o conceito de edição formadora do discurso que se constitui, segundo Nilson Lage, num pilar do jornalismo contemporâneo. Para Lage, dois princípios orientam o jornalismo moderno: o da edição como formadora do discurso, que descende de Eisenstein e Puduvkin, em que os planos ordenados na montagem é que produzem o tema que o diretor pretende mostrar; e o da prevalência da realidade sobre qualquer construção retórica, herdado de André Bazin, o teórico do neo-realismo italiano. Princípios contraditórios, ambos vão se complementar na articulação do discurso jornalístico moderno.

Mesmo o mais cotidiano dos documentários de televisão não 
escapa dessa multiplicidade de instâncias significativas: quando inclui depoimentos e gestos de criaturas, absorve a teatralidade dos relatos e gestos, delimitada pelos padrões de cultura, mas inevitavelmente portadora de sentido. (LAGE, 2004, p. 32)

Até a chegada da televisão, o cinema documental era a mídia que cumpria a função jornalística de representação do real. A história dos noticiários audiovisuais começa com a pré-história dos noticiários do cinema. $\mathrm{O}$ aparecimento do primeiro jornal em imagens se produziu em 1909, por iniciativa dos irmãos Lumiére, ou melhor dito pela Casa Lumiére, que se havia dedicado a registrar em filmes acontecimentos de importância histórica, como por exemplo a coroação do Zar Nicolás II no mês de maio de 1896 . Mas ninguém naquela época via na televisão uma mídia potencialmente comercial, o que fez com que o seu desenvolvimento só começasse efetivamente na década de 50 . (YORK, 2007, p. 11). Essas transmissões, na década de 30 , não chegam, portanto, ainda a desbancar o telecinejornalismo, ou os documentários em película, como meio de informação, material produzido pelos grandes estúdios hollywoodianos e que eram exibidos juntamente com os filmes.

Ao ser lançado, o filme Cidade de Deus se destaca das obras da produção cinematográfica brasileira da pós-modernidade, ao abordar a exclusão social utilizando recursos naturalistas na preparação de atores, mas com uma narrativa que muitos chegaram a qualificar de videoclipe, em imagens totalmente beneficiadas pelas novas tecnologias digitais, da linguagem do vídeo e da televisão comercial, o que facilita o processo de identificação da narrativa pelo público. Inovou, assim, ao conciliar a busca de uma identidade cultural de mercado brasileira com a discussão da realidade brasileira almejada, no passado, por setores da cinematografia brasileira. Uma das influências confessas de Meirelles foi o filme Iracema, a Transamazônica, de Jorge Bodanksy, uma mescla de ficção e documentário que simboliza o impacto desse ideário de despojamento em que o retratado assume sua voz. Kátia Lund, codiretora de CDD, por seu turno, vinha de experiências de documentários e videoclipes com a Videofilmes, produtora de Walter e João Moreira Salles cujos documentários se alinham nitidamente à influência do cinema-direto. Ao menos teoricamente, a idéia do cinema-direto é deixar o entrevistado-personagem falar, sem interferência, e assumir a sua fala da forma mais natural possível, reproduzindo-a.

O cenário privilegiado de filmes como Carandiru é a periferia dos grandes centros urbanos e seus personagens principais - presidiários, traficantes, travestis, desempregados, aposentados - em conflito com a cidade global, a cidade do poder, muitas vezes ausente das imagens. Mas em Cidade de Deus, a neofavela representa uma comunidade fechada, à margem da grande metrópole, um poder paralelo, em ascensão, que vai se revelando completamente integrado à ordem vigente. Exclusão social, violência urbana e periferia, aqui, entretanto, não têm relação com o realismo propagado pelo Cinema Novo, escrito por Glauber Rocha, ou com o conceito de verossimilhança, proposto pelo crítico francês André Bazin em seus estudos sobre cinema, ao se referir ao neo-realismo italiano. Bazin buscava nessa análise uma especificidade da linguagem cinematográfica, num momento em que as concepções de representação 
teatral predominavam nos filmes.

Já o filme de Lund e Meirelles apresentava um projeto estético de cinematografia alinhado às normas da indústria cultural global em consonância com o público regional mas que, ao mesmo tempo, provocava uma ruptura com padrões de discussão da realidade brasileira e do popular, estabelecidos em movimentos cinematográficos anteriores como o Cinema Novo, gerando acaloradas polêmicas e comparações com os filmes que, no passado, abordavam o mesmo tema. A estratégia de não utilizar rostos conhecidos e evitar atores com padrões estéticos de beleza que celebrizassem os padrões adotados pela mídia é um destes recursos, e o outro está no abandono total da norma urbana culta da língua. Essas técnicas já eram utilizadas pelo grupo de teatro Nós do Morro, de Guti Fraga, que forneceu vários de seus integrantes ao filme.

De qualquer forma, como também ocorreu no célebre Rio 40 Graus, outra visão da favela a partir de um olhar paulistano, no caso o de Nelson Pereira dos Santos, e em Cinco Vezes Favela, em Cidade de Deus a personagem principal é, de fato, a comunidade, a favela, e no caso de CDD a neofavela, a cidade global, tal como vai assinalar Octávio. Para ele, as cidades globais são uma síntese privilegiada

\footnotetext{
"do encontro entre a geografia e a história", características dos grandes centros de poder mundiais que se cristalizam em cidades como Los Angeles, São Paulo, Londres, Tóquio, Cidade do México e Rio. Interligadas, elas constituem um sistema mundial de controle da produção e da expansão do mercado" (IANNI, 1999, p. 55).
}

\section{A grande cidade global}

Talvez, mais do que nunca, a questão social adquire todas as características de uma questão simultaneamente urbana. É claro que na grande cidade estão bastante presentes os negócios do narcotráfico e da violência, bem como manifestações de xenofobia, etnocentrismo e racismo, além das carências de recursos habitacionais, de saúde, educação e outros; e, estes já são problemas simultaneamente sociais e urbanos. Envolvem a organização, o desenho e a dinâmica da cidade, implicando arquitetura, urbanismo e planejamento, e revelam-se de modo particularmente acentuado nas grandes cidades, metrópoles, megalópoles. (...) é, frequentemente, nas cidades globais que se localiza a subclasse: uma categoria de indivíduos, famílias, membros das mais diversas etnias e migrantes, que se encontram na condição de desempregados mais ou menos permanentes. São grupos e coletividades, bairros e vizinhanças, nos quais reúnem-se e sintetizam-se todos os principais aspectos da questão social como questão urbana (IANNI, 1999, p. 59,).

Em Cidade de Deus, a neofavela recortada por celulares, metralhadoras e tênis de marca é a terra prometida. Trabalhar na "firma", com os "gerentes" é a única possibilidade de ascensão, a forma que a sociedade civil encontrou de incluir essas pessoas. Neste sentido, vai dialogar muito mais com a temática urbana do Cinema Novo, em produções como a de Nelson Pereira do Santos, de Rio 40 Graus (1955) do que com a obra de Gláuber Rocha. Se, por um lado, coloca personagens comuns, excluídos, como protagonistas, sem nenhum lirismo romântico ou populista, de outro, desafia o conceito de cinema 
autoral de décadas passadas, trabalhando o filme como produto produzido por uma equipe, lançado com estratégia de marketing e parcerias internacionais. A forma como os meninos são retratados também destoa do passado. Os cinco garotos que vendiam amendoim no asfalto para sobreviver possuem uma ingenuidade e uma pureza que, no Brasil dominado pela criminalidade organizada de hoje, não encontra mais lugar. São vítimas: - a câmera mostra a mãe doente de um deles, a infância, sempre presente, de outro que larga o trabalho para brincar no parque. A obra de Nelson, que também como ativista, sempre se preocupou em criar filmes que representassem a cultura brasileira, foi considerada, apesar de ser situada por muitos como um filme que antecede o Cinema Novo, um emblema do filme popular e nacional.

A idéia de um nacionalpopular cultural - e de uma identidade nacional nele baseada - é um tema familiar para toda uma tradição antropológica e literária no Brasil. De Machado de Assis a Carlos Nelson Coutinho, tradutor do italiano Antonio Gramsci, passando por Ferreira Gullar e Mário Pedrosa, Marilena Chauí e até Paulo Emílio Salles Gomes, todos abordaram o tema. Gramsci, um dos fundadores do Partido Comunista Italiano e da corrente conhecida como eurocomunismo foi o primeiro pensador marxista a colocar que a transformação social de uma sociedade burguesa para uma sociedade socialista dar-se-ia, não pela tomada de poder, mas pela conquista de todos os instrumentos de difusão ideológica (escolas, universidades, editoras, meios de comunicação social e sindicatos), uma vez que os principais confrontos ocorrem na esfera cultural e não nas fábricas, nas ruas ou nos quartéis.
Essa visão tornou suas idéias próximas de toda uma geração de intelectuais e produtores culturais, no final dos anos 70, no Brasil. Suas idéias chegaram aqui, pelas mãos de Astrojildo Pereira e Mário Pedrosa, membros do Partido Comunista Brasileiro (PCB), mas a primeira tradução oficial se dá nos anos 60 , através de Carlos Nelson Coutinho.

A noção de atividade cultural e produção da cultura, e por similaridade, da expressão artística como fator de resistência norteia vários movimentos culturais e vai influenciar muitos intelectuais e os próprios CPC. A idéia de um conteúdo nacional, em contraposição ao similar estrangeiro - representado pelo colonizador americano - surge em torno do Cinema Novo, é tema da obra de Paulo Emílio Salles Gomes, e é intrínseca ao famoso manifesto de Glauber Rocha, Estética da Fome.

A proposta de filmes autorais, sem o aparato de grandes produções dos estúdios hollywoodianos, preocupados com uma identidade nacional, a política de autor que, de certa forma, se faz sentir em várias partes do mundo, sobretudo durante o período pós-guerra, quando Hollywood consolida seu império nas salas de exibição européias, se irradia em movimentos como Nouvelle Vague, Neo-Realismo italiano, no Cinema Sueco, e Cinema Novo. Outra crítica que se faz a Cidade de Deus é justamente a de que ele aborda o tema da exclusão social, a partir de uma estética influenciada pelo cinema moderno americano, hollywwodiano, sem se preocupar como um movimento organizado, com um ideário comum de contraposição à hegemonia norteamericana, como ocorreu na década de 60. O que vale para boa parte da produção brasileira deste período, mesmo porque a influência do 
cinema norte-americano sobre a geração de cineastas que emerge da Retomada é evidente.

Bernadet, em sua obra Cineastas e as imagens do povo, sobre o documentário nacional, analisa Viramundo, Aruanda, Opinião Pública e faz uma distinção, necessária, entre obras que retratam o povo e o popular, sob a ótica da ideologia dominante, e de documentários feitos sobre o povo, para o povo, e pelo povo. A obra de Meirelles e Lund, certamente, embora preocupada em imprimir realismo às cenas, se valendo de recursos típicos de documentário, se enquadra perfeitamente no segundo grupo, ainda que feitos para o povo. Esse tipo de discussão reflete questões presentes em todos os movimentos culturais populares dos anos 60 e 70, que irão desembocar no ativismo do vídeo independente dos anos 80. Se, na década de 60 , as idéias de Brecht influenciaram os revolucionários no teatro, ao menos naquilo que se entendia de Brecht naquele momento, no contexto de renovação da linguagem cinematográfica que marcou o início dos anos sessenta, originando movimentos como a Nouvelle Vague na França e o Cinema Novo brasileiro, duas novas posturas de realização de documentários emergiram: o cinema direto e o cinéma vérité, ou cinemaverdade.

Surgido nos Estados Unidos, o cinema direto tornou-se o estilo dominante de documentário, naquele país, influenciando, inclusive, o telejornalismo, e representa uma incorporação, no âmbito do cinema documental, de um ideário de despojamento, realismo e agilidade, similar àquele que, por meio dos movimentos de vanguarda, assinala o início de um dito cinema moderno. Robert Drew e Richard Leacock, respectivamente diretor e fotógrafo do filme "Primary" (1960), são considerados os fundadores do cinema direto e seus principais representantes. No Brasil, o primeiro documentário inspirado pelo cinemadireto foi Opinião Pública, de Arnaldo Jabor.

O cinema-verdade, sobretudo o francês, teve, no antropólogo Jean Rouch, uma expressão máxima. Ao contrário do cinema direto, o cinema-verdade permite e desenvolve o envolvimento do cineasta na ação e, praticamente, o consagra como um personagem, caso de Rouch.

As duas tendências influenciaram gerações de documentaristas e cineastas de ficção, no Brasil e no mundo, como Goddard e Bodansky. Apesar de ideologicamente distintas, enquanto metodologia de produção, ambas concepções estão amparadas pelas inovações tecnológicas, na leveza dos equipamentos, o que possibilita a aplicação de "uma câmera na mão, uma idéia na cabeça", o grande lema do Cinema Novo, e a proximidade com a estrutura da reportagem, na televisão.

A abordagem da temática social, da favela e da periferia não constitui, em si, propriamente, uma novidade e, nem mesmo começou com Rio 40 Graus ou Cinco Vezes Favela (1962). A temática envolvendo a organização habitacional das camadas populares urbanas é bastante tradicional, nas artes brasileiras. Na literatura, está presente desde Memórias de um sargento de milícias (Manuel Antônio de Almeida), de 1853, a obra que serviu ao ensaio de Antônio Cândido $A$ Dialética $d a$ Malandragem, e perpetuou-se em autores tão diferentes entre si, como Aluísio Azevedo, Lima Barreto, Jorge Amado, até chegar ao romance Cidade de Deus, de autoria 
de Paulo Lins, que deu origem ao filme homônimo. Na música popular, as pesquisadoras Jane Souto de Oliveira e Maria Hortense Marcier anotam, já em 1928, um samba de Sinhô, intitulado $A$ favela vai abaixo, e demonstram a recorrência do tema até os dias atuais.

O primeiro tratamento do tema, em cinema, é, provavelmente, Favela dos meus amores (Humberto Mauro, 1935). Desde aquela época, não faltam filmes com referências às favelas, morros e cortiços e cujas orientações ideológicas, de acordo com o pesquisador Arthur Autran, se pautam em geral pelo populismo romântico. Com Rio, 40 graus, obra emblemática do moderno cinema brasileiro, surge uma abordagem mais realista que terá continuidade em Rio, Zona Norte (Nelson Pereira dos Santos, 1957), e em Cinco vezes favela (Leon Hirszman, Joaquim Pedro de Andrade, Carlos Diegues, Marcos Farias e Miguel Borges, 1962) e A grande cidade (Carlos Diegues, 1965).

No caso do documentário, um filme fundamental é Viramundo (Geraldo Sarno, 1965), que aborda a vida dos migrantes nordestinos, em São Paulo. Nos filmes de Coutinho, de Santo Forte a Edifício Master, essa tradição se consolida, de mesmo modo que em Ônibus 174, de José Padilha.

A linguagem coloquial e urbana de Cidade de Deus, a ambientação natural, a utilização de atores desconhecidos para interpretar gente comum e a agilidade dos cortes, que remete à estrutura narrativa dos videoclipes, é distinta daquela evocada por obras do neo-realismo italiano, ou mesmo dos cinemanovistas. No realismo de Meirelles predomina a visão da montagem como articuladora do discurso.
De forma completamente descontextualizada, e sem nenhum intuito revolucionário, os conceitos de montagem de Eisenstein se encontram mais presentes hoje na linguagem dos videoclipes, dos telejornais, dos thrillers de ação do que os conceitos de montagem de Bazin, mais próximos, talvez, da obra de um cineasta como Eduardo Coutinho ou, ainda, Jean Rouch, representantes da linhagem que se tornou conhecida como cinemaverdade.

Uma das críticas que se fez a Cidade de Deus e, posteriormente, a Carandiru, é que, em ambos os filmes, a relação do Estado com a comunidade se resume à presença ostensiva da polícia, e que o problema social e a culpabilidade dessa estrutura não é explicitada. A violência, no filme, se apresentaria de forma espetacularizada, conferindo uma visão maniqueísta às personagens. Dadinho seria intrinsecamente mau e, jamais, fruto de um processo de exclusão social, assim como a invasão ao presídio do Carandiru é totalmente desprovida de caráter político. Em Cidade de Deus não existe lirismo, apenas humor cortante e ironia.

A forma como o filme foi recebido no Brasil e no Exterior é tema da coletânea City of God in Several Voices: Brazillian Social Cinema as Action, organizada pela pesquisadora inglesa Else Vieira e lançada em Londres, em março de 2005, que buscou representar as diferentes percepções de brasileiros e europeus a respeito da questão, ao longo dos artigos do livro.

No artigo City of God: Mastery and Contradictions, Leandro da Rocha Saraiva chama a atenção para o fato de que o filme não julga suas personagens, e a isso se deve muito do choque que ele causa. $O$ filme rompe com uma certa forma de se 
abordar a exclusão social que descende do Cinema Novo, e se encontra em algumas obras do cinema da década de 90.

Na mesma coletânea, Miranda Shaw, em The Brazilian Goodfellas: City of a God as a Gangster Film, compara 24 resenhas publicadas no Exterior, sobretudo nos Estados Unidos, entre 2002 e 2003, a 24 resenhas publicadas no País, e chega à conclusão de que a comparação de Meirelles a Tarantino e Scorcese, se deve, muito mais , a uma tentativa de conquistar o público americano para o filme, apoiada pela Miramax, relacionando-o a um gênero que ele aceita e no qual se reconhece, do que a qualidades intrínsecas ao filme. Os gângsteres de Casino (1995) e Goodfellas (1990), de Martin Scorcese, e de Pulp Ficction (1995) e The Reservoir Dogs (1991), de Quentin Tarantino, resume, mostram personagens integrados à sociedade americana, vitoriosos, ainda que transgredindo a lei. O marginal da neofavela, ainda que triunfando, comandando o tráfico, vive no gueto. Em algumas matérias, o filme foi citado como The Brazillian Goodfellas (SHAW, 2005, p. 58).

0 vídeo independente dos anos 80 e sua contribuição

Tanto os filmes quanto alguns programas considerados inovadores dentro da televisão brasileira de sinal aberto, parte deles abrigados no Núcleo Guel Arraes, da Rede Globo, devem muito aos movimentos alternativos de 80. Fernando Meirelles, que cursou Arquitetura, na Universidade de São Paulo e participou, ao lado de pesquisadores como Arlindo Machado e Roberto Moreira, da extinta revista Cine Olho e de cineclubes, foi um dos articuladores de uma produtora que contribuiu para revolucionar formas de se produzir documentários e jornalismo na televisão, a Olhar Eletrônico. Formada em 1981, por Fernando Meirelles, Paulo Morelli, Marcelo Machado, José Roberto Salatini, Renato Barbieri e Marcelo Tas (os dois últimos integrantes se juntaram, posteriormente, ao grupo), a produtora reunia jovens estudantes, num núcleo que pretendia "revolucionar a linguagem da televisão", nas palavras de Marcelo Tas, o único do grupo original a enveredar, efetivamente, pelo jornalismo. O principal rival da Olhar Eletrônico era a TVDO, liderada por Walter da Silveira e Tadeu Jungle, que chegaram a fundar uma escola em Pinheiros, bairro da Zona Oeste de São Paulo : a Academia Brasileira de Vídeo.

Os novos equipamentos, as ilhas de edição analógicas substituídas pelas digitais, a chegada da televisão a cabo no país e, finalmente, da própria MTV, contribuíam para estimular o fenômeno que ficou conhecido como boom das produtoras. "Com o vídeo pode-se fazer uma "TV fora da TV", isto é, produzir programas, de modo absolutamente independente, sem nenhuma necessidade de uma estrutura de exibição pré-montada" (SANTORO, 1988). Fazer televisão, fora do circuito comercial, era o espírito predominante da década, o que fez surgir inúmeras experiências, fora do mercado. O baixo custo e a facilidade operacional incentivavam a independência, na produção.

No cinema mundial, o primeiro a realçar esse papel iconoclasta do vídeo foi o cineasta Jean-Luc Godard, ao propor, a um grupo de estudantes, em 1969, em Montreal, durante uma reunião na Universidade de Vincennes, que tomassem em mãos um dos instrumentos do poder - um equipamento de vídeo. No caso 
canadense, as tevês comunitárias de Quebec surgiram com o objetivo principal de preservar a identidade cultural dos "quebecoises" de fala francesa, reagindo à invasão indiscriminada dos programas de língua inglesa da televisão americana.

Em outros Estados, grupos independentes realizavam televisões populares também com formatos inovadores e similares, como a TV Viva (Olinda, PE) e a TV Maxabomba (Rio), a TV dos Trabalhadores, ligada ao Sindicato dos Metalúrgicos de São Bernardo do Campo; o Centro de Documentação e Memória Popular; a TV Bixiga, ligada ao Museu Memória do Bixiga, em São Paulo, a primeira emissora de bairro; a TV dos Bancários, ligada ao Sindicato dos Bancários; a Lilith Vídeo, formada por militantes feministas; o Cecip - Centro de Criação da Imagem Popular. Todos esses trabalhos surgem, na década de 80 , não apenas em função de novas tecnologias, mas do processo de redemocratização do país, que se inicia com a Lei de Anistia, em 1979, consolidada pelo crescimento do movimento sindical em 1980, pelo apoio de entidades internacionais como a Fundação Ford - a projetos populares, e que culminaria com o movimento das Diretas Já que levou às eleições diretas, em 1989.

A TV Viva, ligada ao Centro Cultural Luiz Freire, de Olinda, foi criada em 1984, e veiculava seus programas em telões instalados em praças públicas da região metropolitana de Recife e Olinda. Ganharam prêmios em festivais como Vídeo Brasil, em São Paulo, e Festival do Novo Cinema LatinoAmericano, em Havana, chegando a ter programas exibidos na TV Gazeta, em São Paulo, em 1986, em um programa de 30 minutos chamado Ondas Livres. A grande maioria dos trabalhos não tinha por objetivo atingir um circuito comercial e, sim, criar um paralelo, algo que acabou contribuindo para inviabilizar muitos desses projetos, uma vez que a televisão a cabo só entraria no País em 1991, através da TVA, do Grupo Abril, e a concessão de emissoras de rádio e televisão estar concentrada nas mãos de poucas e poderosas empresas e, no caso do telejornalismo, basicamente, limitando-se à Rede Globo. Todas essas intervenções buscavam minar o discurso oficial do jornalismo na televisão e colocar o povo, as pessoas comuns, nas telas. Algumas experiências, como a do Olhar, tinham a pretensão de serem incorporadas pelas emissoras de emissão aberta, outras buscavam preservar a sua independência e invadir as ruas.

Os primeiros a se darem conta das possibilidades do vídeo foram os artistas plásticos. Oficialmente, a história da vídeoarte começa na década de 60 , dentro da proposta "tardo-dadaísta" do grupo Fluxus, que tinha entre seus integrantes John Cage, Nam June Paik e Wolf Vostell. Esse grupo, que surgiu no final dos anos 50 , produziu obras com o intuito de provocar artistas, críticos e consumidores a questionar conceitos e categorias de julgamento, além de se apropriar das novas tecnologias disponíveis para elaborar happenings, performances e festivais. Foi no início daquela década que esses artistas começaram a se interessar pela imagem da televisão, como possibilidade de intervenção estética.

No Brasil, existem relatos sobre o assunto, no final dos anos 60. Os pioneiros foram Antônio Dias, Anna Bella Geiger, José Roberto Aguilar, Ivens Machado, Letícia Parente, Regina Silveira, Júlio Plaza, Paulo Herkenhoff, Regina Vater, Fernando Cocchiarale, Mary Dritschel, Paulo 
Bruscky, Roberto Sandoval, Sônia Andrade. O maior pesquisador de vídeo brasileiro, Arlindo Machado, assinala, entretanto, que a maioria desses artistas já era consagrado quando passa a trabalhar com o vídeo, que eles entendiam ser, apenas, mais um suporte para a sua arte. Muitos desses trabalhos eram incompreensíveis fora da obra do autor. Da mesma forma, essas performances influenciaram obras teatrais, mas, sempre, como um suporte.

Enquanto o vídeo-ativismo criava raízes e se consolidava, nos EUA e em alguns países da Europa, aqui no Brasil essa prática engatinhava. Foi somente nos anos 80, com o início da popularização dos equipamentos de captação e edição, que os primeiros grupos de videomakers começaram a aparecer (FECHINI, 2000).

\section{Abstract}

For most of his history, European cinema's defining aesthetic is realism, which is one of the means by it has traditionally sougth to differentiate itself from Hollywoodian dream machine. In Brazil, though cinema has always gone through periods of ups and downs, the same thing happened. Otherwise, realism is not always the favoured vehicle for the expression of national cultural identity and ideology. Many contemporary realistic productions are hybrid, and they use verisimilitude as artifice.

Keywords: Realism; cultural identity; contemporary cinema; nationalismo.

\section{Referência}

AUTRAN, Arthur. O nacional-popular em "Eles não usam black-tie". Rio de Janeiro: Cinemais, $n^{\circ} 15$, jan.fev., 1999.

BAZIN, André. O cinema: ensaios. São Paulo: Brasiliense, 1991.
BERNADET, Jean-Claude. Cineastas e imagens do povo. São Paulo: Brasiliense, 1993.

BUTCHER, Pedro. A dona da história: origens da Globo Filmes e seu impacto no audiovisual brasileiro. Dissertação (mestrado): Escola de Comunicação/ UFRJ. Rio de Janeiro: Universidade Federal do Rio de Janeiro, 2006.

CEVASCO, Maria Elisa. City of God: the novel reading City of God: Palestra Duke University, Durhan, North Carolina EUA, 2004.

CHAUDHURI, Shohini. Contemporary World Cinema. Edinburgh: Edinburgh University Press, 2005.

EISENSTEIN, S. M. Palavra e Imagem. In: O Sentido do filme. Rio de Janeiro: Jorge Zahar Editor, 1990.

GERBASE, Carlos. Impactos das tecnologias digitais na narrativa cinematográfica. Coleção Comunicação, 30, EdiPUCRS, Porto Alegre, 2003.

GOMES, Paulo Emílio Salles. Cinema: trajetória no subdesenvolvimento. Rio de Janeiro: Paz e Terra; Embrafilmes. (Col. Cinema, V.8), 1980.

IANNI, Octávio. A era do globalismo. Rio de Janeiro: Ed. Civilização Brasileira, 1999.

LAGE, Nilson. Linguagem jornalística. 6. ed. São Paulo: Ática, 1998.

MACHADO, Arlindo. Máquina e imaginário: o desafio das poéticas tecnológicas. São Paulo: EDUSP, 2001.

MATtos, A. C. Gomes de. Do cinetoscópio ao cinema digital: breve história do cinema americano. Rio de Janeiro: Rocco, 2006.

MEIRELLES, Fernando. Do Cine Olho à 02, passando pelo olhar eletrônico. In: Cinemais. n.35. Rio de Janeiro: jul.set., 2003.

MOREIRA, Roberto Franco. Deus 
contra todos. Tese (Doutorado): Escola de Comunicações e Artes. Universidade de São Paulo. São Paulo, 2001.

SALLES, Walter. O documentário como socorro nobre da ficção. In: Cinemais. Rio de Janeiro: ${ }^{\circ}$ 9, jan.fev., 1998.

SANTORO, Luiz Fernando. A Imagem nas mãos: o vídeo popular no Brasil. São Paulo: Summus Editorial, 1989.
SOUZA, Carlos Roberto. A Fascinante Aventura do Cinema Brasileiro. Ed., rev. e aum. São Paulo, SP: Fundação Cinemateca Brasileira, 1981.

VIEIRA, Else. (Org.) City of God in several voices: Brazilian social cinema as action. London: CCCPress, 2005.

YORK., Ivor. Telejornalsimo. São Paulo: Editora Roca, 2007. 